\title{
Resveratrol ameliorates diabetic nephropathy in rats through negative regulation of the $\mathrm{p38}$ MAPK/TGF- $\beta 1$ pathway
}

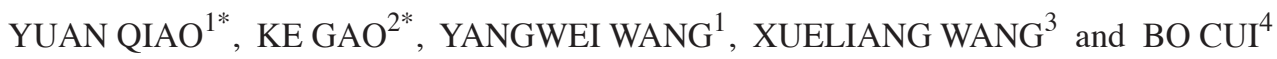 \\ ${ }^{1}$ Department of Endocrinology, Shaanxi Provincial Hospital, Xi'an, Shaanxi 710068; ${ }^{2}$ Department of Neurosurgery, \\ The First Affiliated Hospital of Xi'an Jiaotong University School of Medicine; ${ }^{3}$ Department of Public Health, \\ College of Public Health, Health Science Center, Xi'an Jiaotong University; ${ }^{4}$ Department of Endocrinology, \\ The First Affiliated Hospital of Xi'an Jiaotong University School of Medicine, Xi'an, Shaanxi 710061, P.R. China
}

Received January 5, 2016; Accepted January 20, 2017

DOI: $10.3892 /$ etm.2017.4420

\begin{abstract}
Resveratrol (RSV) has been shown to have a renoprotective effect against diabetic nephropathy, but the underlying mechanisms of this have not been fully elucidated. The aim of the current study was to explore the mechanisms responsible for the therapeutic effects of RSV in rat mesangial cells in vitro and in a rat model of diabetic nephropathy. The viability of CRL-2573 rat mesangial cells and their expression levels of p38, phosphorylated (p)-p38, transforming growth factor beta 1 (TGF- $\beta 1$ ) and fibronectin were assessed in response to treatment with high glucose, with or without RSV. Diabetic nephropathy was also induced in Sprague-Dawley rats by streptozotocin treatment. At 8 weeks, basic biochemical parameters and histopathological abnormalities as well as the expression of p38, p-p38, TGF- $\beta 1$ and fibronectin in rat kidneys were compared between control diabetic rats and those treated with $20 \mathrm{mg} / \mathrm{kg} \mathrm{RSV}$ daily for 4 weeks. In the mesangial cell line, RSV inhibited high glucose-induced increases in cell viability and fibronectin expression by significantly reducing p38 mitogen-activated protein kinase (MAPK) activation and TGF- $\beta 1$ expression $(\mathrm{P}<0.05)$. In diabetic rats, RSV significantly decreased blood glucose, serum creatinine and urinary albumin levels, as well as the kidney weight and ratio of kidney weight/body weight compared with the control group $(\mathrm{P}<0.05)$. Moreover, RSV ameliorated renal histological changes and downregulated the expression of p-p38, TGF- $\beta 1$ and fibronectin in the kidneys of diabetic rats. These data suggested that RSV protected renal
\end{abstract}

Correspondence to: Dr Bo Cui, Department of Endocrinology, The First Affiliated Hospital of Xi'an Jiaotong University School of Medicine, 277 Yanta West Road, Xi'an, Shaanxi 710061, P.R. China E-mail: lianyi8387@163.com

\section{${ }^{*}$ Contributed equally}

Key words: resveratrol, diabetic nephropathy, p38 mitogen-activated protein kinase/transforming growth factor beta 1 pathway tissue from diabetes-induced injury and that this activity may be via inhibition of the $\mathrm{p} 38 \mathrm{MAPK} / \mathrm{TGF}-\beta 1$ signaling pathway.

\section{Introduction}

Diabetic nephropathy is a chronic complication of diabetes that is characterized by the expansion of the glomerular mesangium and excessive accumulation of extracellular matrix (ECM) proteins secreted by the proliferating mesangial cells $(1,2)$. The condition decreases patients' quality of life and is an independent risk factor for end-stage renal disease, thereby increasing the risk of mortality $(3,4)$. The efficacy of current treatments for diabetic nephropathy is unsatisfactory in many patients, and diabetic nephropathy has become the leading cause of chronic dialysis (5). Therefore, a consistently effective therapeutic strategy is urgently required for this condition.

An increasing understanding of the molecular mechanisms underlying diabetic nephropathy offers promising support for the development of effective treatment strategies. Previous studies in humans with diabetic nephropathy as well as experimental animal models of the disease have shown that diabetes and high-glucose conditions cause activation of protein kinase $C(6-8)$ and mitogen-activated protein kinase (MAPK) (9-11) signaling pathways, which serve key functions in cell proliferation, differentiation and apoptosis. The family of MAPKs includes extracellular signal-regulated kinase-1/2, stress-activated c-Jun N-amino terminal kinase (JNK), p38 MAPK and big MAPK $(12,13)$. Additional studies have demonstrated that mediation of transforming growth factor beta 1 (TGF- $\beta 1$ ) by p38 MAPK plays an important role in stimulating cell proliferation and expression of ECM proteins such as fibronectin $(14,15)$.

Resveratrol (RSV) is a natural polyphenolic compound found in various fruits, such as grapes, nuts and berries, as well as in red wine (16). Previous studies have demonstrated that RSV has diverse beneficial health effects including anti-oxidative (17), anti-inflammatory (18), anti-cancer (19), cardioprotective (20) and neuroprotective (21) activities. In relation to diabetic nephropathy, previous reports have indicated that RSV can ameliorate renal insufficiency and pathological changes, as well as prevent high glucose-induced mesangial 
cell proliferation and glomerular fibronectin expression though multiple signaling pathways under diabetic conditions both in vivo and in vitro. These include the PI3K/Akt, JNK/nuclear factor kappa $\mathrm{B}(\mathrm{NF}-\kappa \mathrm{B})$ and $\mathrm{Akt} / \mathrm{NF}-\kappa \mathrm{B}$ pathways $(18,22,23)$. However, to the best of our knowledge, it is not known if a direct link exists between p38 MAPK and TGF- $\beta 1$ in the mechanisms underlying the protective effect of RSV against diabetic nephropathy.

The present study investigated whether RSV treatment could attenuate high glucose-induced mesangial cell viability as well as TGF- $\beta 1$ expression, p38 activation and fibronectin expression in vitro and diabetes-induced changes in renal function and histological changes in vivo. Furthermore, it was examined whether the protective effect of RSV against diabetic nephropathy was due to the inhibition of TGF- $\beta 1$ expression and was dependent on p38 MAPK activation.

\section{Materials and methods}

Rat mesangial cell line culture and treatment. Cells of the rat mesangial cell line CRL-2573 were purchased from the American Type Culture Collection (Manassas, VA, USA) and routinely cultured at $37^{\circ} \mathrm{C}$ in Dulbecco's modified Eagle's medium (DMEM; Invitrogen; Thermo Fisher Scientific, Inc., Waltham, MA, USA) containing $5.6 \mu \mathrm{M}$ glucose (normal glucose) or $25 \mu \mathrm{M}$ glucose (high glucose, $\mathrm{HG}$ ) and $10 \%$ fetal bovine serum (HyClone; GE Healthcare Life Sciences, Logan, UT, USA). In cell viability experiment, cells were treated with $10 \mu \mathrm{M}$ RSV (Cayman Chemical Co., Ann Arbor, MI, USA) or $10 \mu \mathrm{M}$ of an inhibitor of p38 MAPK called SB-203580 (Cayman Chemical Co.) for $48 \mathrm{~h}$, and the medium and agent were replaced daily. The cells were harvested at $48 \mathrm{~h}$. RSV $(10 \mu \mathrm{M})$ and SB-203580 $(10 \mu \mathrm{M})$ were dissolved in dimethyl sulfoxide (DMSO), aliquoted and stored at $-80^{\circ} \mathrm{C}$ until use as treatments. The same volume of DMSO was used as the vehicle control treatment.

Cell viability assay. Cells were seeded in 96-well plates and cultured in DMEM with or without the aforementioned concentrations of $\mathrm{HG}, \mathrm{RSV}$ and SB-203580 at $37^{\circ} \mathrm{C}$ for $48 \mathrm{~h}$. Cell viability was evaluated using a 3-(4,5-dimethylthiazolyl-2)-2,5-diphenyltetrazolium bromide (MTT) assay (24).

Western blot analysis. Cells were lysed on ice using a radioimmunoprecipitation assay buffer (Beyotime Institute of Biotechnology, Haimen, China). Proteins were collected, electrophoresed via $10 \%$ SDS-PAGE, then transferred to polyvinylidene fluoride membranes (Roche Diagnostics $\mathrm{GmbH}$, Mannheim, Germany). Then, the membranes were incubated at $4{ }^{\circ} \mathrm{C}$ overnight with the following primary antibodies: Anti-p38 at a 1:1,000 dilution (ab7952; Abcam, Cambridge, UK), anti-phosphorylated (p)-p38 at a 1:500 dilution (ab4822; Abcam), anti-TGF- $\beta 1$ at a 1:500 dilution (ab92486; Abcam), anti-fibronectin at a 1:500 dilution (ab2413; Abcam) and $\beta$-actin at a 1:1,000 dilution (sc-130656; Santa Cruz Biotechnology, Inc., Dallas, TX, USA). The species-specific horseradish peroxidase-conjugated secondary antibodies (ZDR-5306; ZSGB-Bio, Beijing, China) were added at a 1:500 dilution and incubated for $1 \mathrm{~h}$ at room temperature to the membranes, and immunoreactive protein bands were detected using a Western
Bright Enhanced Chemiluminescence detection system (Advansta, Inc., Menlo Park, CA, USA).

Induction of diabetic rat model and treatment. A total of 50 healthy male Sprague-Dawley rats (8 weeks old, weighing $250 \pm 20 \mathrm{~g}$ ) were obtained from the Animal Experiment Center of Xi'an Jiaotong University (Xi'an, China) and housed under specific pathogen-free conditions. All animals were given ad libitum access to standard food and water and were acclimated for 1 week prior to the beginning of the study. Diabetes was induced using a single dose $(55 \mathrm{mg} / \mathrm{kg})$ of streptozotocin (STZ; Sigma-Aldrich; Merck KGaA, Darmstadt, Germany) injected intraperitoneally, as described previously (25). The STZ was dissolved in cold sodium citrate buffer $(0.1 \mathrm{M}$, $\mathrm{pH} 4.5)$. The normal control $(\mathrm{NG})$ rat group $(\mathrm{n}=10)$ received an injection of the same volume of sodium citrate buffer. Blood glucose levels were measured with a portable glucometer (OneTouch UltraVue ${ }^{\mathrm{TM}}$; LifeScan China, Shanghai, China) in samples from the tail vein at $72 \mathrm{~h}$ after STZ injection, and a plasma glucose level greater than $16.7 \mathrm{mM}$ was considered indicative of diabetes in the rats. The diabetic rats were randomly divided into three groups: Diabetes mellitus (DM) control group $(n=10)$, DM treated with RSV $(\mathrm{DM}+\mathrm{RSV})$ group $(n=10)$ and DM treated with vehicle (DM + DMSO) group $(n=10)$. Eight weeks after STZ treatment to induce diabetes, rats in the DM + RSV group were administered orally with $20 \mathrm{mg} / \mathrm{kg} \mathrm{RSV}$ (dissolved in DMSO and diluted in $0.9 \%$ physiological saline) every day for 4 weeks. Over the same period, rats in the DM + DMSO group were treated with the same volume of vehicle (DMSO) as a control. At the end of these experiments, all animals were anesthetized by $10 \%$ chloral hydrate $(300 \mathrm{mg} / \mathrm{kg})$ and sacrificed by venous air embolism for subsequent analysis. This study was approved by the Ethics Committee of the First Affiliated Hospital of Xi'an Jiaotong University School of Medicine.

Histological examination and immunohistochemistry. Rat kidneys were removed, fixed in $10 \%$ formalin solution and embedded in paraffin. Sections of $5-\mu \mathrm{m}$ thickness were cut from the fixed kidney tissue, deparaffinized, hydrated and stained using hematoxylin and eosin. Histological properties were examined using an Olympus BX51 polarizing microscope (Olympus Corporation, Tokyo, Japan). For immunohistochemical staining, 5- $\mu \mathrm{m}$ paraffin-embedded tissue sections were prepared on poly-L-lysine-coated microscope slides. These sections were then deparaffinized, hydrated and incubated in $0.3 \% \mathrm{H}_{2} \mathrm{O}_{2} /$ methanol for $10 \mathrm{~min}$ at $25^{\circ} \mathrm{C}$ to quench endogenous peroxidase activity. The slides were boiled at $100^{\circ} \mathrm{C}$ for $10 \mathrm{~min}$ in $1 \%$ citrate buffer $(\mathrm{pH} 6.0)$ for antigen retrieval and then blocked with blocking solution containing goat serum (ZSGB-Bio, Beijing China). Sections were incubated with polyclonal antibodies against p38 (1:100; ab7952; Abcam, Cambridge, UK), phosphorylated (p)-p38 (1:200; ab4822; Abcam), TGF- $\beta 1$ (1:500; ab92486; Abcam), or fibronectin (1:500; ab2413; Abcam) overnight at $4^{\circ} \mathrm{C}$. After incubation with a biotinylated secondary antibody (1:20; Bangalore GeNei; Merck KGaA, Darmstadt, Germany; Stored at $-20^{\circ} \mathrm{C}$ ) at $25^{\circ} \mathrm{C}$ for $40 \mathrm{~min}$, horseradish peroxidase was applied to the sections and diaminobenzidine was used as the chromogen. Finally, the sections were counterstained with 
A

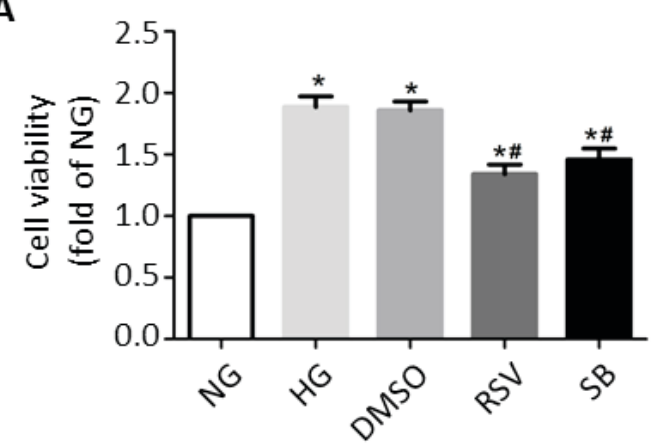

B
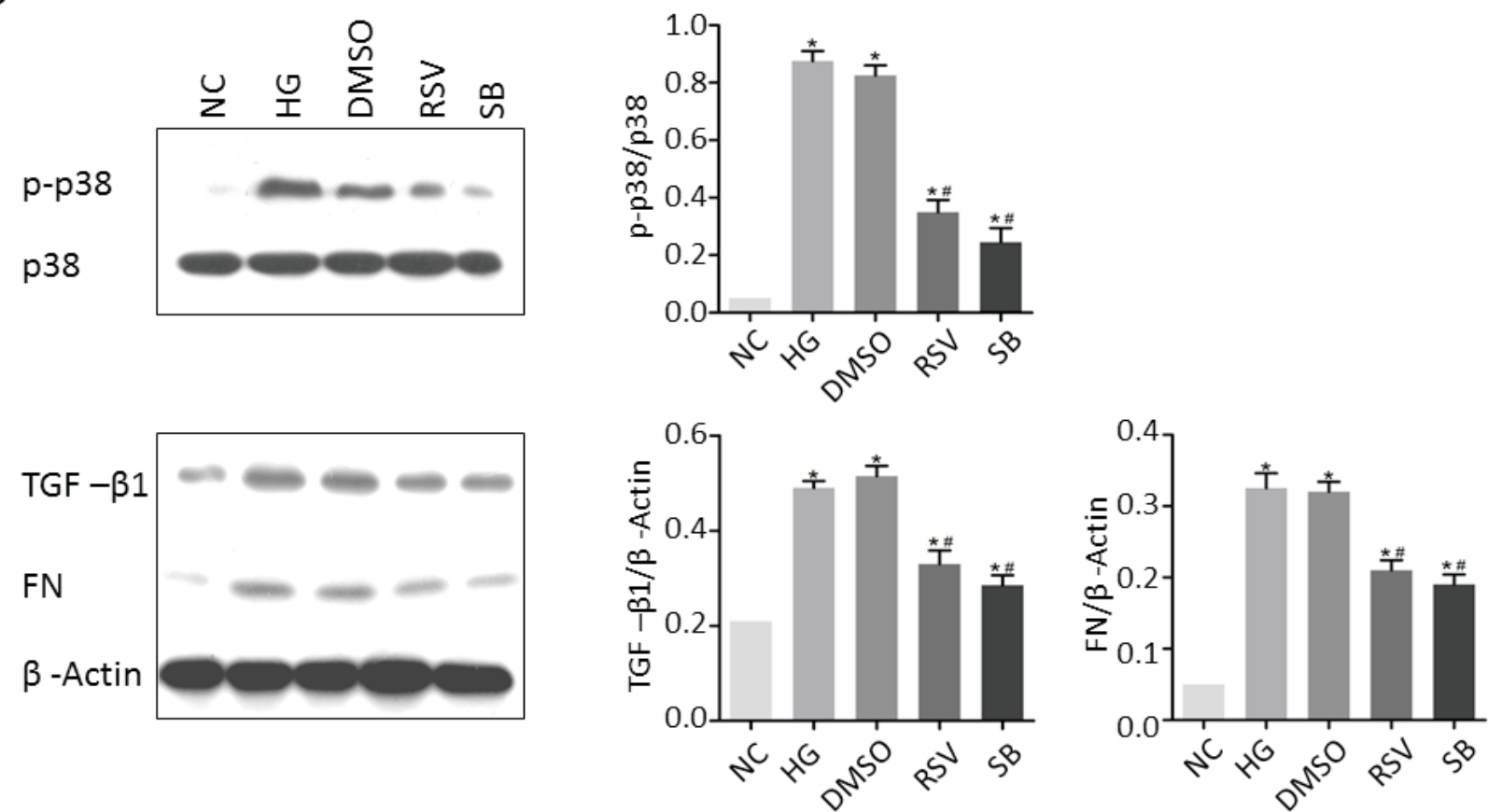

Figure 1. Effect of RSV treatment following exposure to high glucose in the mesangial cell line CRL-2573. (A) Relative levels of cell viability among CRL-2573 cells treated with NG, HG, HG + vehicle (DMSO), HG + RSV, or HG + SB. (B) Representative western blot analysis showing p-p38, TGF- $\beta 1$ and fibronectin expression in CRL-2573 cells treated with NG, HG, HG + vehicle (DMSO), HG + RSV or HG + SB, and the corresponding quantitative data. "P<0.05 vs. NG, ${ }^{\text {\#P}} \mathrm{P} 0.05$ vs. HG. NG, normal glucose; HG, high glucose; RSV, resveratrol; DMSO, dimethyl sulfoxide; SB, SB-203580; p-p38, phosphorylated-p38; TGF- $\beta 1$, transforming growth factor beta $1 ; \mathrm{FN}$, fibronectin.

hematoxylin and examined by light microscopy. Image-Pro Plus 6.0 software (Media Cybernetics, Inc. Rockville, MD, USA) was used for quantitative analysis of the immunohistochemical staining results.

Statistical analysis. Statistical analysis was performed using the Student's $t$-test and SPSS 16.0 software (SPSS, Inc., Chicago, IL, USA). All data are expressed as the mean \pm standard deviation of three independent experiments. $\mathrm{P}<0.05$ was considered to indicate a statistically significant difference.

\section{Results}

High glucose induced rat mesangial cell viability, TGF- $\beta 1$ expression and fibronectin expression by promoting $p 38$ MAPK activation. First, the effect of high glucose on the
CRL-2573 rat mesangial cell line in vitro. As shown in Fig. 1A, treatment of rat mesangial cells with $25 \mu \mathrm{M}$ glucose for $24 \mathrm{~h}$ led to significantly increased cell viability as compared with a normal glucose treatment of $5.6 \mu \mathrm{M}(\mathrm{P}<0.05)$. In addition, treatment with high glucose significantly increased TGF- $\beta 1$ and fibronectin expression ( $\mathrm{P}<0.05$ for both) and significantly promoted p38 activation, resulting in upregulation of p-p38 $(\mathrm{P}<0.05)$. These results suggest that exposure to high glucose caused rat mesangial cells to proliferate, express increased levels of TGF- $\beta 1$ and fibronectin and exhibit increased levels of $\mathrm{p} 38$ activation.

To further examine the association of rat mesangial cell viability, TGF- $\beta 1$ expression and fibronectin secretion with p38 activation, cells were simultaneously treated with high glucose and the p38 inhibitor SB-203580 $(25 \mu \mathrm{M})$ for $24 \mathrm{~h}$. Treatment with SB-203580 significantly inhibited the high 
Table I. Effects of resveratrol on basic biochemical parameters in study rats ( $\mathrm{n}=10$ per group).

\begin{tabular}{lcccc}
\hline Parameter & NG & DM & DM + DMSO & DM + RSV \\
\hline Food intake $(\mathrm{g} / \mathrm{d})$ & $108.56 \pm 8.23$ & $210.43 \pm 11.97^{\mathrm{a}}$ & $230.55 \pm 17.19^{\mathrm{a}}$ & $123.57 \pm 9.05^{\mathrm{a}-\mathrm{c}}$ \\
Water intake $(\mathrm{ml} / \mathrm{d})$ & $250.12 \pm 15.03$ & $950.66 \pm 36.89^{\mathrm{a}}$ & $930.51 \pm 27.71^{\mathrm{a}}$ & $380.49 \pm 20.01^{\mathrm{a}-\mathrm{c}}$ \\
Urine output $(\mathrm{ml} / \mathrm{d})$ & $157.21 \pm 6.01$ & $965.42 \pm 21.58^{\mathrm{a}}$ & $872.30 \pm 25.34^{\mathrm{a}}$ & $350.48 \pm 9.18^{\mathrm{a}-\mathrm{c}}$ \\
Blood glucose $(\mathrm{mM})$ & $4.64 \pm 0.68$ & $26.32 \pm 7.78^{\mathrm{a}}$ & $25.99 \pm 8.32^{\mathrm{a}}$ & $18.85 \pm 5.64^{\mathrm{a}-\mathrm{c}}$ \\
Serum creatinine $(\mathrm{mM})$ & $30.24 \pm 4.56$ & $58.21 \pm 8.11^{\mathrm{a}}$ & $59.76 \pm 9.03^{\mathrm{a}}$ & $46.62 \pm 7.08^{\mathrm{a}-\mathrm{c}}$ \\
Urinary albumin $(\mathrm{mg} / \mathrm{dl})$ & $4.09 \pm 0.52$ & $12.89 \pm 0.96^{\mathrm{a}}$ & $12.38 \pm 0.89^{\mathrm{a}}$ & $8.36 \pm 0.45^{\mathrm{a}-\mathrm{c}}$ \\
Body weight $(\mathrm{g})$ & $458.25 \pm 11.97$ & $338.06 \pm 10.38^{\mathrm{a}}$ & $347.77 \pm 15.37^{\mathrm{a}}$ & $361.05 \pm 12.45^{\mathrm{a}}$ \\
Kidney weight $(\mathrm{g})$ & $2.64 \pm 0.26$ & $3.31 \pm 0.19^{\mathrm{a}}$ & $3.48 \pm 0.11^{\mathrm{a}}$ & $2.92 \pm 0.23^{\mathrm{a}-\mathrm{c}}$ \\
Kidney weight/body weight $(\mathrm{g} / \mathrm{kg})$ & $5.89 \pm 0.11$ & $10.09 \pm 0.13^{\mathrm{a}}$ & $10.15 \pm 0.09^{\mathrm{a}}$ & $7.93 \pm 0.18^{\mathrm{a}-\mathrm{c}}$ \\
\hline
\end{tabular}

NG, normal control group; DM, diabetes mellitus control group; DM + DMSO, diabetic rats treated with vehicle; DM + RSV, diabetic rats treated with RSV. ${ }^{\mathrm{P}}<0.05$ vs. $\mathrm{NG},{ }^{\mathrm{b}} \mathrm{P}<0.05$ vs. $\mathrm{DM}$. ${ }^{\mathrm{C}} \mathrm{P}<0.05$ vs. $\mathrm{DM}+\mathrm{DMSO}$.

glucose-induced viability of rat mesangial cell as well as the high glucose-induced upregulation of TGF- $\beta 1$ and p-p38, and increased fibronectin accumulation ( $\mathrm{P}<0.05$ for all; Fig. 1B). These results suggest that the increases in viability and TGF- $\beta 1$ and fibronectin expression observed in rat mesangial cells exposed to high glucose are mediated via p38 activation.

RSV inhibited high glucose-induced rat mesangial cell viability, TGF- $\beta 1$ expression and fibronectin secretion by inhibiting p38 activation. Next, the effects of RSV on rat mesangial cells exposed to high glucose were investigated in vitro. Cells were treated with $25 \mu \mathrm{M}$ glucose, or $25 \mu \mathrm{M}$ glucose $+25 \mu \mathrm{M}$ RSV, or $25 \mu \mathrm{M}$ glucose + DMSO vehicle for $24 \mathrm{~h}$. Vehicle treatment had no effect on the viability of cells exposed to high glucose, but treatment with RSV resulted in a significant reduction in cell viability compared with high glucose treatment alone $(\mathrm{P}<0.05$; Fig. 1A). Consistently, vehicle treatment had no effect on the upregulation of $\mathrm{p}-\mathrm{p} 38$, TGF- $\beta 1$ and fibronectin in cells exposed to high glucose, whereas RSV treatment led to significant decreases in p-p38, TGF- $\beta 1$ and fibronectin expression compared with high glucose treatment alone $(\mathrm{P}<0.05$ for all; Fig. 1B). These effects of RSV were similar to those of SB-203580 in rat mesangial cells (Fig. 1B). Together these results suggest that RSV inhibited the high glucose-induced viability, upregulated TGF- $\beta 1$ and increased fibronectin secretion by inhibiting p38 activation.

Effects of RSV on basic biochemical parameters in diabetic rats. After STZ injection, rats that developed diabetes exhibited increases in food intake, water intake and urine output (Table I). At the end of the study, the mean body weight of rats with diabetes in all treatment groups (DM, DM + DMSO and $\mathrm{DM}+\mathrm{RSV}$ ) was significantly lower than that of the NG rats $(\mathrm{P}<0.05$; Table $\mathrm{I})$. In addition, diabetic rats of the $\mathrm{DM}$, $\mathrm{DM}+\mathrm{DMSO}$ and DM + RSV groups exhibited significantly higher blood glucose concentration, serum creatinine concentration, urinary albumin concentration, kidney weight and ratio of kidney weight/body weight compared with rats in the NG group $(\mathrm{P}<0.05$; Table I). Treatment of diabetic rats with RSV had no effect on body weight, but significantly reduced the aforementioned increases in blood glucose concentration, serum creatinine concentration, urinary albumin concentration, kidney weight and ratio of kidney weight/body weight compared with rats in the DM and DM + DMSO groups $(\mathrm{P}<0.05$; Table I).

RSV ameliorated diabetes-induced histological changes in the rat kidney. Light microscopy images of kidney sections from NG rats showed the normal structure of the glomerulus and tubules (Fig. 2A). Compared to this, the kidneys of rats with STZ-induced diabetes (DM and DM + DMSO groups) showed histological changes, such as glomerular thickening, interstitial fibrosis, epithelial cellular vacuolar degeneration, hyaline casts and arteriolopathy (Fig. 2B and C). Treatment with RSV attenuated the interstitial and glomerular alterations in the kidneys of diabetic rats (Fig. 2D). The histological changes observed in the kidneys of rats from each experimental group were scored ('-' represents the number of changes $\leq 10 \%$; ' + ' represents the number of changes $>10 \%$ and $\leq 40 \%$; ' ++ ' represents the number of changes $>40 \%$ and $\leq 70 \%$; ' +++ ' represents the number of changes $>70 \%$ and $\leq 100 \%$ ), and the results are summarized in Table II.

RSV attenuated p38 MAPK activation, TGF- $\beta 1$ expression and fibronectin accumulation in kidneys of diabetic rats. Immunohistochemical analysis revealed the absence of p38 and p-p38 expression in control kidneys. Quantification of immunohistochemical staining indicated a significant increase in p38 and p-p38 in the distal tubules, collecting ducts, occasional proximal tubules and glomeruli of the kidneys of rats with STZ-induced diabetes compared with normal control rats $(\mathrm{P}<0.05$; Fig. 3, DM and DM + DMSO groups). Staining of kidney sections from rats treated with RSV (DM + RSV group) showed that RSV significantly suppressed the upregulation of p38 and p-p38 compared with the DM group $(\mathrm{P}<0.05)$. Quantification of immunohistochemical staining for TGF- $\beta 1$ showed the same trends, with significantly increased expression in the DM and DM + DMSO groups compared with the control $(\mathrm{P}<0.05)$, which was significantly decreased in the $\mathrm{DM}+\mathrm{RSV}$ group compared with the DM group $(\mathrm{P}<0.05$; Fig. 3). 
A

$\mathrm{C}$

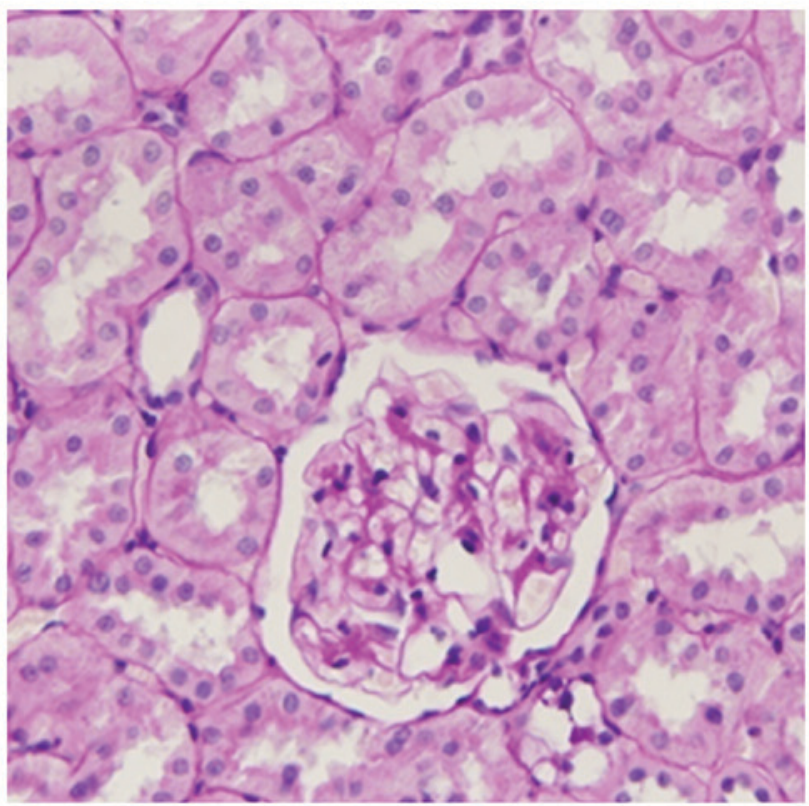

B

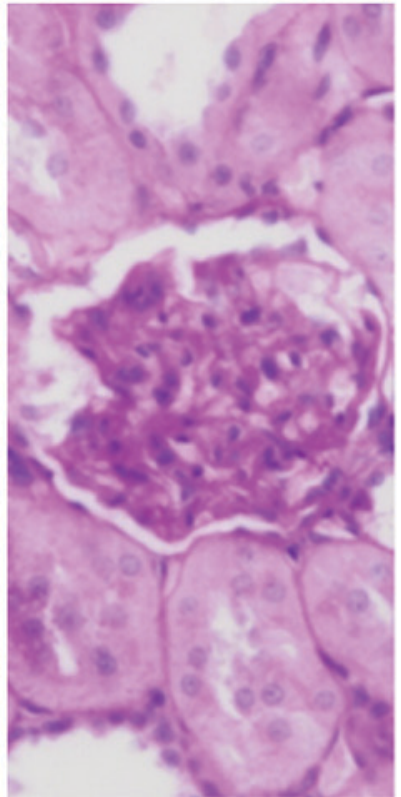

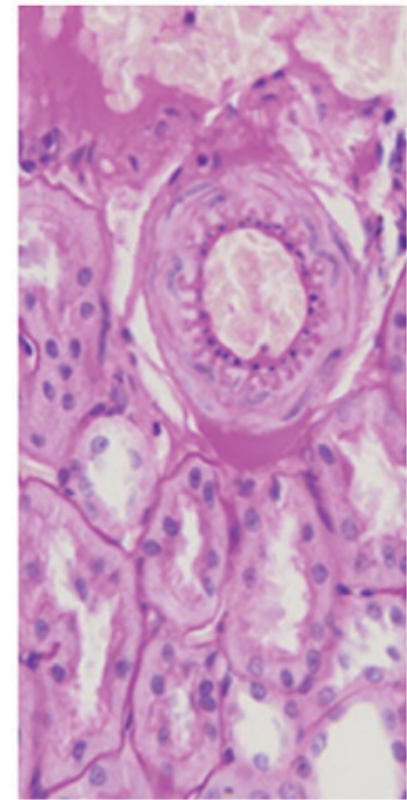

$\mathrm{D}$

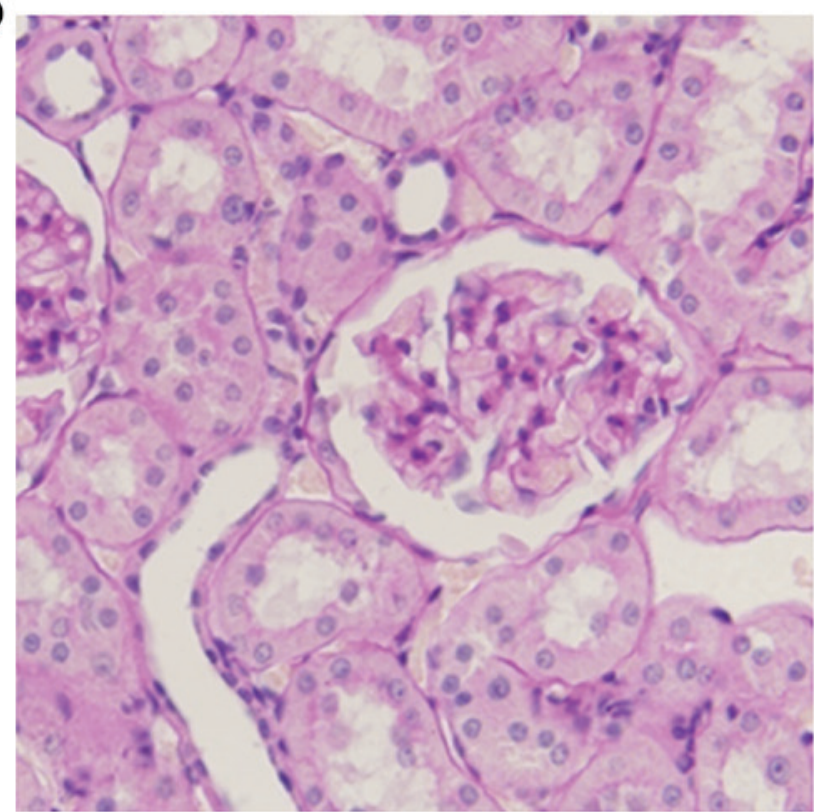

Figure 2. Hematoxylin and eosin staining of kidney sections from diabetic rats with and without RSV treatment. (A) Normal glomerulus and tubules of an NG rat. (B) Glomerulus and tubules of a DM rat. Glomerular thickening, interstitial fibrosis and hyaline changes, epithelial cellular vacuolar degeneration, hyaline casts and arteriolopathy are visible. (C) Glomerulus and tubules of a DM rat treated with DMSO vehicle control. Histological alterations of glomeruli and arterioles are similar to those observed in the DM group. (D) Glomerulus and tubules of a DM rat treated with RSV. Milder histological alterations of glomeruli and arterioles are observed. Magnification, x400. NG, normal control group; DM, diabetes mellitus control group; DM + DMSO, diabetic rats treated with vehicle; DM + RSV, diabetic rats treated with RSV. The dark blue color represents the nuclei and the pink color represents cytoplasm, fibronectin and red blood cells.

In addition, significantly increased accumulation of the ECM protein fibronectin, a known indicator of diabetic nephropathy, was seen in the kidneys of rats with diabetes (DM and DM + DMSO groups) compared with the control group. However, kidney sections from rats in the DM + RSV group showed significantly reduced accumulation of fibronectin compared with the DM group ( $\mathrm{P}<0.05$; Fig. 3$)$.

\section{Discussion}

RSV has previously been shown to protect against renal insufficiency and pathological changes associated with diabetic nephropathy both in vivo and in vitro $(18,22,23)$. However, the mechanisms responsible for these renoprotective effects remain poorly understood. Increased p38 MAPK activation has been found in the glomeruli of kidneys from animal models of diabetes $(26,27)$ and in mesangial cells cultured under high-glucose conditions (28). These findings suggest that the p38 MAPK pathway may serve a key function in diabetic nephropathy. Moreover, the p38 MAPK pathway is activated by several stress factors that occur in the process of the diabetic nephropathy development, such as hyperglycemia $(28,29)$, hemodynamic abnormalities $(30)$, oxidative stress (31) and proinflammatory cytokines (32). Enhanced 
Table II. Results of histopathological examination of kidneys of rats in all experimental groups.

\begin{tabular}{lcccc}
\hline Feature & NG & DM & DM + DMSO & DM + RSV \\
\hline Apical blebbing & - & +++ & +++ \\
Glomerular thickening & - & +++ & +++ & + \\
Interstitial fibrosis & - & ++ & +++ \\
Arteriolopathy & - & ++ & +++ \\
Hyaline casts & - & ++ & + \\
\hline
\end{tabular}

NG, normal control group; DM, diabetes mellitus control group; DM + DMSO, diabetic rats treated with vehicle; DM + RSV, diabetic rats treated with RSV; -, none; +, mild; ++, moderate; +++, severe.
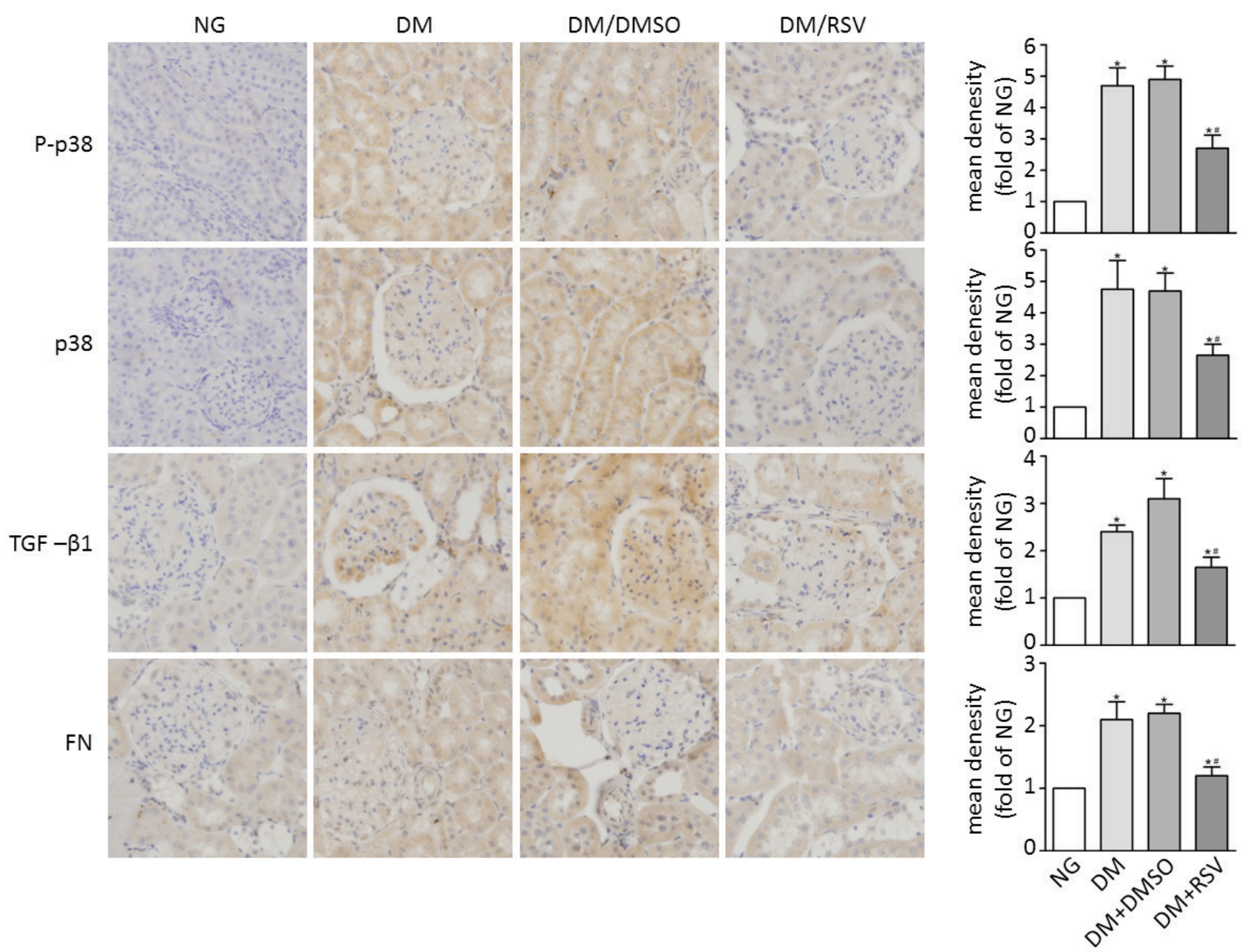

Figure 3. Immunohistochemical staining of kidney sections from diabetic rats with and without RSV treatment. Kidney sections from rats in each experimental group were examined by immunohistochemical staining for p-p38, p38, TGF- $\beta 1$ and fibronectin (magnification, $x 400$ ). Quantitative relative density data are shown on the right. NG, normal control group; DM, diabetes mellitus control group; DM + DMSO, diabetic rats treated with vehicle; DM + RSV, diabetic rats treated with RSV; p-p38, phosphorylated-p38; TGF- $\beta 1$, transforming growth factor beta 1 ; FN, fibronectin. ${ }^{*} \mathrm{P}<0.05$ vs. NG, ${ }^{*} \mathrm{P}<0.05$ vs. DM. The blue color represents nuclei and the brown color represents the assessed protein.

expression of p-p38, as a key signaling molecule in the p38 MAPK pathway, is a marker of activation of this signaling pathway (33). Activation of p38 MAPK induces inflammatory cell activation, promotes inflammatory mediator expression and mediates cytokine production, all of which are critical events leading to renal tissue injury in diabetic nephropathy. TGF- $\beta 1$, as a key cytokine, plays a pivotal role in promoting cell viability and increasing ECM production in diabetic 
nephropathy (34), and the role of p38 MAPK activation in the progression of diabetic nephropathy in both humans and experimental animals has been linked to its induction of TGF- $\beta 1$ expression (35). Nevertheless, the effect of RSV treatment on p38 MAPK/TGF- $\beta 1$ signaling in diabetic nephropathy has remained unclear. In the present study, it was hypothesized that RSV exerts its renoprotective effects in diabetic nephropathy by inhibiting TGF- $\beta 1$ through suppression of $\mathrm{p} 38$ MAPK activation.

To test this hypothesis, the effects of high glucose and RSV on cell viability and expression of p38, p-p38, TGF- $\beta 1$ and fibronectin were evaluated using the CRL-2573 mesangial cell line. It was found that high glucose significantly increased p38 MAPK activity and TGF- $\beta 1$ expression in mesangial cells as well as their viability and fibronectin expression. These results are consistent with those of previous studies $(23,36,37)$. For example, Wilmer et al (29) reported that TGF- $\beta 1$ is critically involved in mesangial cell viability and fibronectin expression. The p38 activity inhibitor SB-203580 was also used to demonstrate that the increases in mesangial cell viability and fibronectin expression induced by exposure to high glucose via upregulation of TGF- $\beta 1$ were dependent on p38 MAPK activation. Furthermore, RSV treatment significantly inhibited the high glucose-induced increases in p38 MAPK activation, TGF- $\beta 1$ expression, cell viability and fibronectin expression in mesangial cells. These findings supported the hypothesis that RSV acts through p38 MAPK/TGF- $\beta 1$ signaling to inhibit high glucose-induced changes in mesangial cells.

The current study also investigated the mechanisms underlying the effects of RSV on renal function and histological abnormalities in rats with STZ-induced diabetes. At 8 weeks after STZ injection, the rats demonstrated typical characteristics of diabetic nephropathy such as hyperglycemia, polyuria and weight loss, and increases in serum creatinine, urinary albumin excretion and the ratio of kidney weight/body weight. Moreover, kidneys from these mice showed pathological changes such as glomerular thickening, interstitial fibrosis and hyaline changes, epithelial cellular vacuolar degeneration, hyaline casts and arteriolopathy. Treatment with RSV significantly reduced these changes in biochemical parameters as well as the pathological alterations observed in diabetic rats. Via immunohistochemical staining, it was observed that RSV treatment also reduced p38 MAPK activation and the expression of downstream molecules including TGF- $\beta 1$ and fibronectin in the diabetic rat kidney. These findings further indicate that $\mathrm{p} 38 \mathrm{MAPK} / \mathrm{TGF}-\beta 1$ signaling plays a role in the renoprotective effects of RSV in a rodent model of diabetic nephropathy.

In conclusion, both the in vitro findings in high glucose-treated mesangial cells and the in vivo findings in rats with STZ-induced diabetes demonstrated that the renoprotective effects of RSV involve the attenuation of p38 MAPK activation as well as reduced expression of TGF- $\beta 1$ and fibronectin. Thus, we propose that $\mathrm{p} 38 \mathrm{MAPK} / \mathrm{TGF}-\beta 1$ signaling is inhibited by RSV. The results of the present study provide insight into the mechanisms responsible for diabetic nephropathy, as well as the related effects of RSV. This could be applied in the development of an effective therapeutic strategy for treating this chronic complication of diabetes.

\section{Acknowledgements}

This study was supported by the Science and Technology Fund of Shaanxi Province (project no. 2013K12-09-05).

\section{References}

1. Miyauchi M, Toyoda M, Kobayashi K, Abe M, Kobayashi T, Kato M, Yamamoto N, Kimura M, Umezono T and Suzuki D: Hypertrophy and loss of podocytes in diabetic nephropathy. Intern Med 48: 1615-1620, 2009.

2. Meng XM, Huang XR, Xiao J, Chen HY, Zhong X, Chung AC and Lan HY: Diverse roles of TGF- $\beta$ receptor II in renal fibrosis and inflammation in vivo and in vitro. J Pathol 227: 175-188, 2012.

3. Hill KE, Gleadle JM, Pulvirenti M and McNaughton DA: The social determinants of health for people with type 1 diabetes that progress to end-stage renal disease. Health Expect 18: 2513-2521, 2015.

4. Nakagawa T, Lan HY, Glushakova O, Zhu HJ, Kang DH, Schreiner GF, Böttinger EP, Johnson RJ and Sautin YY: Role of ERK1/2 and p38 mitogen-activated protein kinases in the regulation of thrombospondin-1 by TGF-betal in rat proximal tubular cells and mouse fibroblasts. J Am Soc Nephrol 16: 899-904, 2005.

5. Haneda M, Utsunomiya K, Koya D, Babazono T, Moriya T, Makino H, Kimura K, Suzuki Y, Wada T, Ogawa S, et al: A new classification of diabetic nephropathy 2014: A report from joint committee on diabetic nephropathy. Clin Exp Nephrol 19: 1-5, 2015.

6. Soetikno V, Watanabe K, Sari FR, Harima M, Thandavarayan RA, Veeraveedu PT, Arozal W, Sukumaran V, Lakshmanan AP, Arumugam S and Suzuki K: Curcumin attenuates diabetic nephropathy by inhibiting PKC- $\alpha$ and PKC- $\beta 1$ activity in streptozotocin-induced type I diabetic rats. Mol Nutr Food Res 55: 1655-1665, 2011.

7. Zhou L, Dong H, Huang Y, Xu L, Zou X, Wang K, Chen G and $\mathrm{Lu}$ F: Hu-Lu-Ba-Wan attenuates diabetic nephropathy in type 2 diabetic rats through $\mathrm{PKC}-\alpha / \mathrm{NADPH}$ oxidase signaling pathway. Evid Based Complement Alternat Med 2013: 504642, 2013.

8. Thallas-Bonke V, Jha JC, Gray SP, Barit D, Haller H, Schmidt HH, Coughlan MT, Cooper ME, Forbes JM and Jandeleit-Dahm KA: Nox-4 deletion reduces oxidative stress and injury by PKC- $\alpha$-associated mechanisms in diabetic nephropathy. Physiol Rep 2: pii: e12192, 2014.

9. Toyoda M, Suzuki D, Honma M, Uehara G, Sakai T, Umezono T and Sakai H: High expression of PKC-MAPK pathway mRNAs correlates with glomerular lesions in human diabetic nephropathy. Kidney Int 66: 1107-1114, 2004.

10. Lu HJ, Tzeng TF, Liou SS, Da Lin S, Wu MC and Liu IM: Polysaccharides from Liriopes Radix ameliorate streptozotocin-induced type I diabetic nephropathy via regulating $\mathrm{NF}-\kappa \mathrm{B}$ and p38 MAPK signaling pathways. BMC Complement Altern Med 14: 156, 2014

11. Zhang L, Zhang J, Liu X, Liu S and Tian J: Tribbles 3 regulates the fibrosis cytokine TGF- $\beta 1$ through ERK1/2-MAPK signaling pathway in diabetic nephropathy. 2014: 240396, 2014.

12. Barr RK and Bogoyevitch MA: The c-Jun N-terminal protein kinase family of mitogen-activated protein kinases (JNK MAPKs). Int J Biochem Cell Biol 33: 1047-1063, 2001.

13. Shin HJ, Choi MS, Ryoo NH, Nam KY, Park GY, Bae JH, Suh SI, Baek WK, Park JW and Jang BC: Manganese-mediated up-regulation of HIF-1alpha protein in Hep2 human laryngeal epithelial cells via activation of the family of MAPKs. Toxicol In Vitro 24: 1208-1214, 2010.

14. Naito T, Masaki T, Nikolic-Paterson DJ, Tanji C, Yorioka N and Kohno N: Angiotensin II induces thrombospondin-1 production in human mesangial cells via p38 MAPK and JNK: A mechanism for activation of latent TGF-beta1. Am J Physiol Renal Physiol 286: F278-F287, 2004.

15. Wei J, Li Z, Chen W, Ma C, Zhan F, Wu W and Peng Y: AEG-1 participates in TGF-beta1-induced EMT through p38 MAPK activation. Cell Biol Int 37: 1016-1021, 2013.

16. Rajasekaran D, Elavarasan J, Sivalingam M, Ganapathy E, Kumar A, Kalpana K and Sakthisekaran D: Resveratrol interferes with N-nitrosodiethylamine-induced hepatocellular carcinoma at early and advanced stages in male Wistar rats. Mol Med Rep 4: 1211-1217, 2011. 
17. Haohao Z, Guijun Q, Juan Z, Wen K and Lulu C: Resveratrol improves high-fat diet induced insulin resistance by rebalancing subsarcolemmal mitochondrial oxidation and antioxidantion. J Physiol Biochem 71: 121-131, 2015.

18. Xu F, Wang Y, Cui W, Yuan H, Sun J, Wu M, Guo Q, Kong L, $\mathrm{Wu} \mathrm{H}$ and Miao L: Resveratrol prevention of diabetic nephropathy is associated with the suppression of renal inflammation and mesangial cell Proliferation: Possible Roles of Akt/NF- $\mathrm{B}$ Pathway. Int J Endocrinol 2014: 289327, 2014.

19. Singh CK, Ndiaye MA and Ahmad N: Resveratrol and cancer: Challenges for clinical translation. Biochim Biophys Acta 1852: 1178-1185, 2015.

20. Mokni M, Hamlaoui S, Karkouch I, Amri M, Marzouki L, Limam F and Aouani E: Resveratrol provides cardioprotection after ischemia/reperfusion injury via modulation of antioxidant enzyme activities. Iran J Pharm Res 12: 867-875, 2013.

21. Kumar A, Negi G and Sharma SS: Neuroprotection by resveratrol in diabetic neuropathy: Concepts \& mechanisms. Curr Med Chem 20: 4640-4645, 2013.

22. Kim MY, Lim JH, Youn HH, Hong YA, Yang KS, Park HS Chung S, Ko SH, Shin SJ, Choi BS, et al: Resveratrol prevents renal lipotoxicity and inhibits mesangial cell glucotoxicity in a manner dependent on the AMPK-SIRT1-PGC1 $\alpha$ axis in $\mathrm{db} / \mathrm{db}$ mice. Diabetologia 56: 204-217, 2013.

23. Zhang L, Pang S, Deng B, Qian L, Chen J, Zou J, Zheng J, Yang L, Zhang C, Chen X, et al: High glucose induces renal mesangial cell proliferation and fibronectin expression through JNK/NF- $\kappa \mathrm{B} / \mathrm{NADPH}$ oxidase/ROS pathway, which is inhibited by resveratrol. Int J Biochem Cell Biol 44: 629-638, 2012

24. Cui B, Yang Q, Guan H, Shi B, Hou P and Ji M: PRIMA-1, a mutant p53 reactivator, restores the sensitivity of TP53 mutant-type thyroid cancer cells to the histone methylation inhibitor 3-Deazaneplanocin A. J Clin Endocrinol Metab 99: E962-E970, 2014.

25. Schmatz R, Perreira LB, Stefanello N, Mazzanti C, Spanevello R, Gutierres J, Bagatini M, Martins CC, Abdalla FH, Daci da Silva Serres J, et al: Effects of resveratrol on biomarkers of oxidative stress and on the activity of delta aminolevulinic acid dehydratase in liver and kidney of streptozotocin-induced diabetic rats. Biochimie 94: 374-383, 2012.

26. Kang SW, Adler SG, Lapage J and Natarajan R: p38 MAPK and MAPK kinase $3 / 6$ mRNA and activities are increased in early diabetic glomeruli. Kidney Int 60: 543-552, 2001.
27. Wang J, Huang H, Liu P, Tang F, Qin J, Huang W, Chen F, Guo F, Liu W and Yang B: Inhibition of phosphorylation of p38 MAPK involved in the protection of nephropathy by emodin in diabetic rats. Eur J Pharmacol 553: 297-303, 2006.

28. Tsiani E, Lekas P, Fantus IG, Dlugosz J and Whiteside C: High glucose-enhanced activation of mesangial cell p38 MAPK by ET-1, ANG II, and platelet-derived growth factor. Am J Physiol Endocrinol Metab 282: E161-E169, 2002.

29. Wilmer WA, Dixon CL and Hebert C: Chronic exposure of human mesangial cells to high glucose environments activates the p38 MAPK pathway. Kidney Int 60: 858-871, 2001.

30. Ingram AJ, Ly H, Thai K, Kang MJ and Scholey JW: Mesangial cell signaling cascades in response to mechanical strain and glucose. Kidney Int 56: 1721-1728, 1999.

31. Yamada T, Egashira N, Bando A, Nishime Y, Tonogai Y, Imuta M, Yano T and Oishi R: Activation of p38 MAPK by oxidative stress underlying epirubicin-induced vascular endothelial cell injury. Free Radic Biol Med 52: 1285-1293, 2012.

32. Soetikno V, Sari FR, Veeraveedu PT, Thandavarayan RA, Harima M, Sukumaran V, Lakshmanan AP, Suzuki K, Kawachi $\mathrm{H}$ and Watanabe K: Curcumin ameliorates macrophage infiltration by inhibiting NF- $\mathrm{kB}$ activation and proinflammatory cytokines in streptozotocin induced-diabetic nephropathy. Nutr Metab (Lond) 8: 35, 2011.

33. Cuadrado A and Nebreda AR: Mechanisms and functions of p38 MAPK signalling. Biochem J 429: 403-417, 2010.

34. Li Y, Chen Q, Liu FY, Peng YM, Wang S, Li J, Li J, Duan SB, Sun L, Ling GH and Luo JH: Norcantharidin inhibits the expression of extracellular matrix and TGF- $\beta 1$ in HK- 2 cells induced by high glucose independent of calcineurin signal pathway. Lab Invest 91: 1706-1716, 2011.

35. Fujita H, Omori S, Ishikura K, Hida M and Awazu M: ERK and p38 mediate high-glucose-induced hypertrophy and TGF-beta expression in renal tubular cells. Am J Physiol Renal Physiol 286: F120-F126, 2004.

36. Hoffman BB, Sharma K, Zhu Y and Ziyadeh FN: Transcriptional activation of transforming growth factor-betal in mesangial cell culture by high glucose concentration. Kidney Int 54: 1107-1116, 1998.

37. Jeong SI, Kim SJ, Kwon TH, Yu KY and Kim SY: Schizandrin prevents damage of murine mesangial cells via blocking NADPH oxidase-induced ROS signaling in high glucose. Food Chem Toxicol 50: 1045-1053, 2012. 